\title{
How does Fetal Autopsy after Pregnancy Loss or Termination for Anomalies and other Complications Change Recurrence Risk?
}

\author{
Arianna Cassidy, MD ${ }^{1}$ Claire Herrick, MD ${ }^{2}$ Mary E. Norton, MD ${ }^{1}$ Philip C. Ursell, MD ${ }^{3}$ \\ Juan Vargas, $\mathrm{MD}^{1}$ Jennifer L. Kerns, MD, $\mathrm{MPH}^{1}$ \\ ${ }^{1}$ Department of Obstetrics, Gynecology, and Reproductive Sciences, \\ University of California, San Francisco, California \\ ${ }^{2}$ Department of Obstetrics and Gynecology, University of Arizona, \\ Tucson, Arizona \\ Address for correspondence Jennifer L. Kerns, MD, MPH, Department \\ of Obstetrics, Gynecology, and Reproductive Sciences, University of \\ California, San Fransisco, School of Medicine, 1001 Potrero Avenue \\ Ward 6D, San Francisco, CA 94110 (e-mail: Jennifer.kerns@ucsf.edu).
}

${ }^{3}$ Department of Pathology, University of California, San Francisco, California

Am J Perinatol Rep 2019;9:e30-e35.

\begin{abstract}
Keywords

- fetal autopsy

- pregnancy termination

- anomalies

- pregnancy complications

- recurrence risk

Objective Historically, fetal autopsy was common after terminations for anomalies. Previous studies report that fetal autopsy confirms ultrasound findings in the majority of cases. This study aims to examine correlation between prenatal and autopsy diagnoses at University of California, San Francisco (UCSF) and evaluate whether autopsy adds diagnostic information, specifically information that changes risk of recurrence for future pregnancies.

Study Design We conducted a retrospective chart review of all fetal autopsies performed at UCSF between 1994 and 2009. Prenatal diagnosis was compared with autopsy diagnosis; for cases where there was a change in diagnosis, an MFM (maternalfetal medicine specialist) reviewed the case to assign risk of recurrence before and after autopsy.

Results Overall, there was concordance between prenatal diagnosis and autopsy diagnosis in greater than $91.7 \%$ of cases. Autopsy added information that resulted in a change in recurrence risk in $2.3 \%$ of cases $(n=9)$.

Conclusion For the vast majority of cases, there is agreement between prenatal and autopsy diagnosis after pregnancy loss or termination for fetal anomalies. Only a small percentage of autopsies change recurrence risk. This may be useful when counseling women about method of termination and when counseling couples about whether to have an autopsy.
\end{abstract}

Fetal autopsy is commonly recommended in cases of fetal anomaly of unknown etiology and fetal demise. ${ }^{1}$ Historically, autopsy was a common practice after terminations to ascertain ultrasound accuracy. ${ }^{2-4}$ More recently, however, fetal autopsy is being performed less frequently, especially when the reason for the anomaly is known, such as with chromo- somal abnormalities. $^{2-5}$ In cases of multiple or complex malformations of undetermined cause, fetal autopsy often is still performed. ${ }^{3,4}$

Fetal autopsy can serve as a quality assurance measure for prenatal diagnostic tools, which may provide psychological benefit for patients, and can help to elucidate the etiology of received

October 16, 2018

accepted

October 19, 2018
DOI https://doi.org/

10.1055/s-0039-1681013. ISSN 2157-6998.
Copyright $\odot 2019$ by Thieme Medical

Publishers, Inc., 333 Seventh Avenue, New York, NY 10001, USA. Tel: +1(212) 584-4662.
License terms

(요 $\Theta \circledast$ 
intrauterine fetal demise. ${ }^{4}$ Determining the cause of demise or anomaly that led to pregnancy loss or termination is important not only to determine the recurrence risk but also to identify options to avoid recurrence, for example, using gamete donors or preimplantation genetic diagnosis. In addition, as an increasing number of causative genes are identified, autopsy can help to guide genetic testing for suspected disorders. In cases, in which a specific gene mutation is identified, this can be used for prenatal diagnosis with chorionic villus sampling (CVS) or amniocentesis. Most studies report that fetal autopsy confirms ultrasound findings in the majority of cases, with additional findings discovered in a wide range of cases (2-50\% of autopsies). ${ }^{2-14}$ Ultrasound and autopsy findings correlate most closely in cases of major central nervous system (CNS) $)^{12,15,16}$ and genitourinary abnormalities; autopsy adds the most information in cases of cardiac, facial, and musculoskeletal abnormalities, information that may prove useful in counseling patients about their risk of recurrence in subsequent pregnancies.

We aimed to investigate correlation of specific prenatal diagnoses with fetal autopsy findings and change in recurrence risk according to fetal autopsy findings overall and for specific diagnoses. This information could be useful in counseling patients about whether to pursue additional testing and may affect healthcare providers' recommendations for particular prenatal diagnoses.

\section{Methods}

We performed a retrospective cohort review of all fetal autopsies performed at the University of California, San Francisco (UCSF), a tertiary care referral center, between 1994 and 2009. We identified all fetal autopsies performed in this time period from a database maintained in the pathology department. Specialists in developmental pathology complete all fetal autopsies at UCSF according to standard practices.

We included all autopsies performed in cases of intrauterine fetal demise, termination for anomalies, or fetuses delivered but not resuscitated. Reasons for termination included preterm premature rupture of membranes (PPROM), previable preterm labor, genetic (genetic anomaly, meaning diagnosis through CVS, or amniocentesis) and/or structural anomalies, and maternal indications. We included fetuses that were a part of a multiple pregnancy individually. We excluded cases in which the fetus survived more than 6 hours after delivery and terminations that were done for reasons other than anomalies or pregnancy complications. We excluded cases with any documentation of resuscitation efforts. We also excluded cases of preterm delivery and subsequent neonatal death, as we could not exclude the possibility of attempted resuscitation. We excluded cases in which the fetus was sent from an outside institution postmortem for autopsy, as there was minimal documentation about prenatal diagnosis available, and therefore we could not verify the quality of prenatal diagnostic methods. In addition, we excluded cases where only a partial autopsy was performed (i.e., CNS only) and those where either prenatal or postnatal information was unavailable. We reviewed medical charts for all cases of fetal autopsy that met our inclusion criteria. The data we abstracted included fetal autopsy reports, prenatal testing information and diagnoses (i.e., ultrasound findings, number of ultrasounds performed, additional imaging), and amniocentesis or chorionic villus sampling results. We reviewed ultrasound reports and when reports were unavailable, we reviewed descriptions of ultrasound findings in clinical notes. We included the latter because, though they were incomplete, they still provided useful summaries of prenatal diagnosis. We also collected the following data on maternal and fetal characteristics: maternal age, gravidity, and parity, gestational age at the time of delivery/dilation and evacuation, and mode of delivery (induction of labor, dilation and evacuation, or other). This study was approved by the Committee on Human Research at UCSF.

We compared prenatal diagnoses to autopsy diagnoses for all cases. Maternal-fetal medicine subspecialists (J.V., M.E.N.) reviewed all cases with disparate findings. For each case, they assigned recurrence risk before autopsy to be low risk (< $25 \%$ ), high risk ( $>25 \%$ ), or unknown; and recurrence risk after autopsy to be low risk, high risk, or unknown. Then, they determined change in recurrence for each case as follows: no change, change from low risk to high risk, change from high risk to low risk, or unknown. We used descriptive analyses by reporting proportions of change in recurrence risk overall and according to particular diagnoses.

\section{Results}

A total of 434 fetal autopsies were performed during the study period. We excluded 49 cases, which left 385 cases for analysis (-Fig. 1).

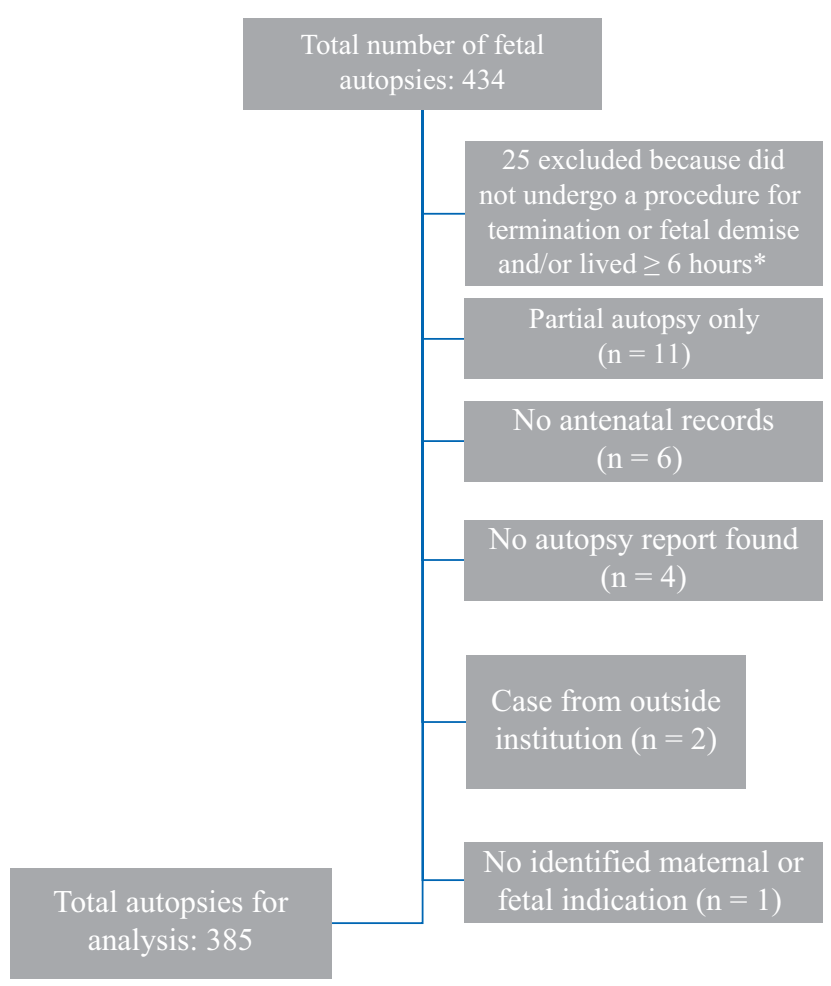

Fig. 1 Exclusions and total autopsies for analysis. *Documentation of any resuscitation efforts and/or neonate lived $>6$ hours following delivery. 
The mean age of women for whom fetal autopsies were performed was 29 years, with an average gestational age at time of delivery or termination of $23^{5 / 7}$ weeks ( $\mathbf{- T a b l e ~} \mathbf{1}$ ). Approximately one-third of women were white and onethird of them were other/unknown. Most terminations were accomplished by induction of labor ( $n=356 ; 92.5 \%)$, with the remainder done by dilation and evacuation $(n=11$; $2.9 \%$ ), or other methods including hysterotomy and unspecified methods ( $n=18 ; 4.7 \%)$. Notably, $71(18.4 \%)$ of the

Table 1 Characteristics of patients in whom autopsies were done after pregnancy termination

\begin{tabular}{|c|c|}
\hline & $n(\%)$ \\
\hline Total & 385 \\
\hline Maternal age (y) & 29.0 (range: 13-46) \\
\hline $\begin{array}{l}\text { Gestational age at the time of } \\
\text { termination or delivery (wk) }\end{array}$ & 23.7 (range: 14-41.4) \\
\hline Gravidity & $3(1-15)$ \\
\hline Parity & $1(0-6)$ \\
\hline \multicolumn{2}{|l|}{ Race } \\
\hline White & $129(33.5)$ \\
\hline Black & $56(14.5)$ \\
\hline Asian/Pacific Islander/Hawaiian & $34(8.8)$ \\
\hline Hispanic/Latina & $50(13.0)$ \\
\hline Native American & $1(0.3)$ \\
\hline Other/unknown & $115(29.9)$ \\
\hline \multicolumn{2}{|l|}{ Mode of termination } \\
\hline Induction & $356(92.5)$ \\
\hline$D \& E$ & $11(2.9)$ \\
\hline Hysterotomy & $8(2.1)$ \\
\hline Unknown & $10(2.6)$ \\
\hline Singleton pregnancy & $314(81.6)$ \\
\hline Multiple pregnancy & $71(18.4)$ \\
\hline \multicolumn{2}{|l|}{ Reason for autopsy } \\
\hline Genetic anomaly & $29(7.5)$ \\
\hline Structural anomaly & $154(40.0)$ \\
\hline Preterm labor (previable) & $42(10.9)$ \\
\hline PPROM & $44(11.4)$ \\
\hline Intrauterine fetal demise & $107(27.8)$ \\
\hline With known anomaly & $48(12.5)$ \\
\hline Without known anomaly & $59(15.3)$ \\
\hline Maternal morbidity & $9(2.3)$ \\
\hline Preeclampsia & $5(1.3)$ \\
\hline HELLP syndrome & $2(0.5)$ \\
\hline Mirror syndrome & $1(0.3)$ \\
\hline Malignancy & $1(0.3)$ \\
\hline
\end{tabular}

Abbreviations: D\&E, dilation and evacuation; HELLP, hemolysis, elevated liver enzymes, and low platelets; PPROM, previable preterm premature rupture of membranes. fetuses included in this study were the product of a multiple pregnancy (twins or triplets). Structural anomalies were the most common reason for autopsy ( $n=154 ; 40 \%$ ) followed by intrauterine fetal demise ( $n=107 ; 27.8 \%)$.

Overall, there was agreement between prenatal diagnosis and autopsy diagnosis in greater than $91.7 \%$ of cases. Autopsy added information that resulted in a change in recurrence risk in $2.3 \%$ of cases ( $n=9$; - Table 2 ).

For cases of prenatally diagnosed structural abnormalities, $17.5 \%$ ( $n=27)$ had a change in diagnosis; of these, $3.9 \%$ ( $n=6 ; 1.6 \%$ of total cases) had a change in recurrence risk based on autopsy findings. We observed the highest incidence of change in diagnosis in cases of musculoskeletal anomalies (40\%; $n=5$ ), neurological anomalies (23.3\%; $n=9$ ), and multiple anomalies $(18.9 \% ; n=10)$. Cases of intrauterine growth restriction/oligohydramnios and facial anomalies had high incidence but only one or two cases of each (-Fig. 2). Reasons for termination with the highest incidence of change in recurrence risk were neurological $(10 \% ; n=3)$ and genitourinary $(5.2 \% ; n=1)$, followed by multiple anomalies (3.8\%; $n=2)$.

Of the 48 autopsies performed for intrauterine fetal demise with a known anomaly (i.e., diagnosed prenatally), there were two cases in which autopsy provided information that changed recurrence risk from low to high. In the 42 autopsies done for preterm previable PPROM, three had a change in diagnosis but only two had a change in recurrence (both low to high).

There were two terminations for structural anomalies in which autopsies revealed no clear structural malformations. In one, prenatal ultrasound showed, probable DandyWalker, malformation with inferior vermian agenesis. The patient was counseled to have a repeat ultrasound in 2 weeks but instead elected to terminate via induction of labor at $20^{4 /}$

${ }^{7}$ weeks. In another case, the ultrasound showed an IUGR fetus with renal agenesis resulting in lung hypoplasia, bilateral ventriculomegaly with possible corpus callosum agenesis, and an abnormal placenta; on autopsy, the fetus had no malformations (though the CNS was too macerated for complete evaluation) but the placenta showed massive perivillous fibrin deposition.

\section{Discussion}

In this retrospective review of the correlation between ultrasound and autopsy diagnoses in fetuses that were terminated, we found full agreement between prenatal and postnatal diagnosis in $91.7 \%$ of cases but a change in recurrence risk in only $2.3 \%$.

Our findings are similar to studies that have found ultrasound-autopsy concordance in 29 to $91 \%$ of cases. ${ }^{17,18}$ However, our findings on the change in recurrence risk differ from those of other studies that demonstrate a recurrence risk of 8 to $49 \%$. Boyd et $\mathrm{al}^{2}$ reviewed 309 terminations for anomalies and found that in $27 \%$ of cases, information from the autopsy changed recurrence risk. In 2007, Dickinson et $\mathrm{al}^{3}$ conducted a 10-year review of 1,012 terminations for fetal abnormality and found that in $16 \%$ of euploid cases, 
Does Fetal Autopsy Change Recurrence Risk after Pregnancy Loss? Cassidy et al. e33

Table 2 Cases with change in recurrence risk after autopsy

\begin{tabular}{|c|c|c|}
\hline Prenatal diagnosis & Autopsy diagnosis & Change in recurrence risk \\
\hline $\begin{array}{l}\text { Anhydramnios with bilateral echogenic } \\
\text { kidneys }\end{array}$ & Renal tubular dysgenesis & Unknown to high \\
\hline Hydrops, bilateral clubfeet, hypokinesis & Neu-Laxova Syndrome & Unknown to high \\
\hline Skeletal dysplasia & Kyphomelic dysplasia & Unknown to high \\
\hline $\begin{array}{l}\text { Dandy-Walker malformation, multiple } \\
\text { anomalies }\end{array}$ & Fryns's syndrome & Unknown to high \\
\hline $\begin{array}{l}\text { IUFD with intracranial arteriovenous malfor- } \\
\text { mation, high output cardiac failure }\end{array}$ & $\begin{array}{l}\text { No major malformations but severe intrauterine } \\
\text { growth restriction and very small placenta ( } 114 \\
\text { gm, expected } 457 \text { gm), IUFD from chronic } \\
\text { hypoxia secondary to placental insufficiency }\end{array}$ & Low to high \\
\hline $\begin{array}{l}\text { Fetal renal agenesis versus severe renal dys- } \\
\text { plasia resulting in anhydramnios and hypo- } \\
\text { plastic lungs }\end{array}$ & $\begin{array}{l}\text { No malformations, placenta with massive peri- } \\
\text { villous fibrin deposition }\end{array}$ & Low to high \\
\hline Ventriculomegaly, elevated alpha-fetoprotein & Congenital Finnish type nephrotic syndrome & Low to high \\
\hline $\begin{array}{l}\text { Elevated maternal alpha-fetoprotein and } \\
\text { human chorionic gonadotropin, possible Fin- } \\
\text { nish nephrosis }\end{array}$ & $\begin{array}{l}\text { No major malformations, kidneys with fused foot } \\
\text { processes consistent with Finnish type congeni- } \\
\text { tal nephrosis }\end{array}$ & Low to high \\
\hline $\begin{array}{l}\text { Encephalocele, intrauterine growth } \\
\text { restriction }\end{array}$ & $\begin{array}{l}\text { Radial aplasia, meningoencephalocele, cerebellar } \\
\text { hypoplasia consistent with Dandy-Walker variant }\end{array}$ & Low to unknown \\
\hline
\end{tabular}

Abbreviation: IUFD, intrauterine fetal demise.

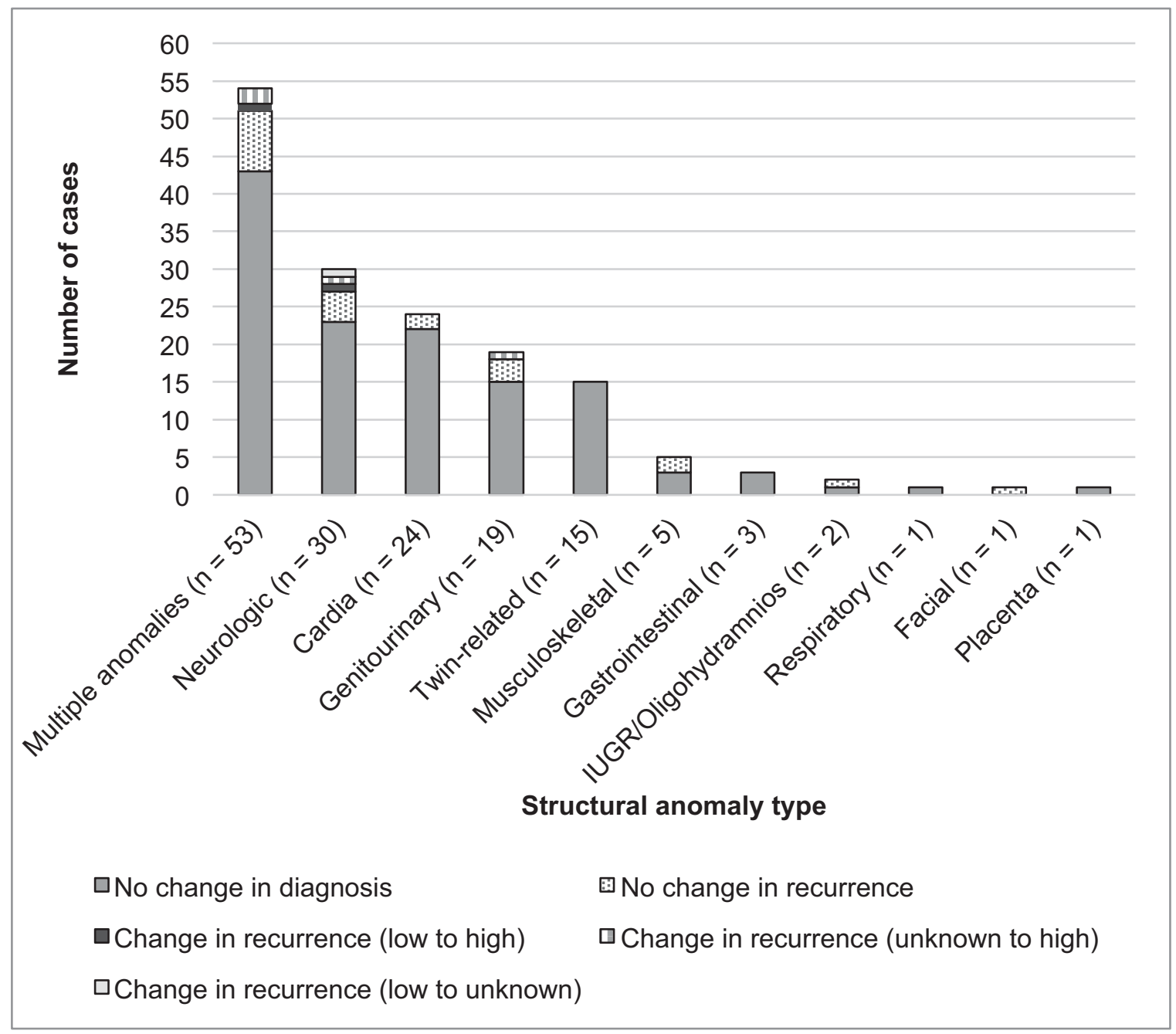

Fig. 2 Change in recurrence by reason for termination. 
autopsy added "significant or major information"; of these, there was a change in recurrence risk in $49 \%$ ( $8 \%$ of all euploid cases). Both had much higher proportions of terminations for karyotypic abnormalities than ours. Our lower rate reflects the skill of the radiologists at our institution and may also reflect population differences.

There is increasing evidence that minimally invasive fetal autopsy is a highly accurate alternative to conventional autopsy. ${ }^{19}$ Postmortem magnetic resonance imaging (MRI) is especially useful in the evaluation of many fetal CNS pathologies, as it may not be as limited by maceration and autolysis that result from a termination. ${ }^{20-22}$ The less invasive approach has also been found to have higher acceptability among parents. ${ }^{23}$

In our cohort, the vast majority of fetuses were delivered via labor induction. It is not explicitly stated in the medical records why the proportion of labor inductions is so high in this cohort, though in our cohort most people choosing autopsy underwent induction.

Notably, among cases of PPROM, preterm labor and maternal morbidity which made up approximately $25 \%$ of our population, there was only one case of previable preterm labor in which estimation of recurrence risk changed after autopsy. In cases, such as these, autopsy may be less useful, especially with regards to implications for future pregnancies.

Strengths of our study include the fact that we looked at all fetal autopsies performed at our tertiary referral center. We included a broader gestational age than other comparable studies. Our fetal ultrasonographers are expert in discerning detailed anatomy and our pathologists are highly trained in fetal autopsy and follow a specific protocol to standardize diagnoses.

We had some limitations in the records that were incorporated due to multiple different medical records systems over the study period. This meant that for some cases, we had to rely on clinical notes that summarized prenatal diagnoses rather than more complete formal ultrasound reports. Unfortunately, we were not able to consistently evaluate which patients underwent a postnatal genetic study (such as karyotype, microarray, or other analysis); nor were we able to consistently evaluate which patients underwent postnatal MRI. The results from this testing were not consistently available in the electronic or physical charts. Additionally, there was variation in the method of diagnosis in our study population. The majority of diagnoses were made at the time of detailed anatomic survey by a radiologist or maternal-fetal medicine specialist with formal training in obstetric ultrasound, but for a small percentage of the cases we relied on the ultrasound diagnosis from a different institution, or a less detailed ultrasound; for five cases, prenatal imaging information was missing completely. Another limitation to our study (and other studies in the literature) is lack of baseline recurrence risk for each couple's condition. Finally, this is a tertiary care center, so results may not be generalizable to hospitals without highly specialized prenatal diagnostic services.

\section{Conclusion}

Our study reaffirms that for the vast majority of cases at our institution, there is high agreement between prenatal and autopsy diagnosis after pregnancy termination for fetal anomalies. There is variation in that concordance according to anomaly type, for example, autopsy is particularly useful in the case of musculoskeletal anomalies where fetal ultrasound cannot provide the anatomic detail necessary for accurate diagnosis. Of course, autopsy remains a method of analyzing quality control for ultrasound. But what is most meaningful to patients is understanding whether they are at risk for future pregnancies that may be affected by the same condition. Further studies that take into account a couple's prenatal recurrence risk for specific conditions would be useful. Patients should be informed that in most cases, autopsy may not result in useful information. Such counseling may be particularly relevant for women who are deciding to terminate by induction of labor versus dilation and evacuation (D\&E) and feel compelled to choose induction of labor because they believe it will yield more information from an autopsy; based on our findings, desire for an autopsy should not be a deciding factor. ${ }^{24}$

\section{Funding Sources}

Author A.C. was supported by the UCSF Dean's Office Medical Student Research Program.

\section{Conflict of Interest}

None.

\section{References}

1 ACOG Practice Bulletin No. ACOG practice bulletin no. 102: management of stillbirth. Obstet Gynecol 2009;113(03):748-761

2 Boyd PA, Tondi F, Hicks NR, Chamberlain PF. Autopsy after termination of pregnancy for fetal anomaly: retrospective cohort study. BMJ 2004;328(7432):137

3 Dickinson JE, Prime DK, Charles AK. The role of autopsy following pregnancy termination for fetal abnormality. Aust N Z J Obstet Gynaecol 2007;47(06):445-449

4 Picone O, Levaillant J-M, Hirt R, Frydman R, Boulvain M, Senat M$\mathrm{V}$. Correlation between referral ultrasound with suspected foetal anomalies and autopsy examination in two prenatal diagnosis centres. Impact of the routine use of $3 \mathrm{D} / 4 \mathrm{D}$ scan. Prenat Diagn 2008;28(03):191-196

5 Parkar AP, Olsen ØE, Maartmann-Moe H, Daltveit AK, Gjelland K, Rosendahl K. Antenatal ultrasound and postnatal autopsy findings in terminations after 12 weeks' gestation due to fetal abnormality: population-based study in Western Norway, 1988-2002. Acta Radiol 2009;50(07):816-822

6 Akgun H, Basbug M, Ozgun MT, et al. Correlation between prenatal ultrasound and fetal autopsy findings in fetal anomalies terminated in the second trimester. Prenat Diagn 2007;27(05):457-462

7 Amini H, Antonsson P, Papadogiannakis N, et al. Comparison of ultrasound and autopsy findings in pregnancies terminated due to fetal anomalies. Acta Obstet Gynecol Scand 2006;85(10): 1208-1216

8 Antonsson P, Sundberg A, Kublickas M, et al. Correlation between ultrasound and autopsy findings after 2nd trimester terminations of pregnancy. J Perinat Med 2008;36(01):59-69 
9 Isaksen CV, Eik-Nes SH, Blaas HG, Torp SH. Comparison of prenatal ultrasound and postmortem findings in fetuses and infants with central nervous system anomalies. Ultrasound Obstet Gynecol 1998;11(04):246-253

10 Isaksen CV, Eik-Nes SH, Blaas HG, Tegnander E, Torp SH. Comparison of prenatal ultrasound and postmortem findings in fetuses and infants with congenital heart defects. Ultrasound Obstet Gynecol 1999;13(02):117-126

11 Johns N, Al-Salti W, Cox P, Kilby MD. A comparative study of prenatal ultrasound findings and post-mortem examination in a tertiary referral centre. Prenat Diagn 2004;24(05):339-346

12 Kaasen A, Tuveng J, Heiberg A, Scott H, Haugen G. Correlation between prenatal ultrasound and autopsy findings: a study of second-trimester abortions. Ultrasound Obstet Gynecol 2006;28(07):925-933

13 Stubblefield PG, Carr-Ellis S, Borgatta L. Methods for induced abortion. Obstet Gynecol 2004;104(01):174-185

14 Sun CC, Grumbach K, DeCosta DT, Meyers CM, Dungan JS. Correlation of prenatal ultrasound diagnosis and pathologic findings in fetal anomalies. Pediatr Dev Pathol 1999;2(02):131-142

15 Grimes DA, Smith MS, Witham AD. Mifepristone and misoprostol versus dilation and evacuation for midtrimester abortion: a pilot randomised controlled trial. BJOG 2004;111(02):148-153

16 Piercecchi-Marti MD, Liprandi A, Sigaudy S, et al. Value of fetal autopsy after medical termination of pregnancy. Forensic Sci Int 2004;144(01):7-10

17 Godbole K, Bhide V, Nerune S, Kulkarni A, Moghe M, Kanade A. Role of fetal autopsy as a complementary tool to prenatal ultrasound. J Matern Fetal Neonatal Med 2014;27(16): 1688-1692

18 Rodriguez MA, Prats P, Rodríguez I, Cusí V, Comas C. Concordance between prenatal ultrasound and autopsy findings in a tertiary center. Prenat Diagn 2014;34(08):784-789

19 Thayyil S, Sebire NJ, Chitty LS, et al; MARIAS collaborative group. Post-mortem MRI versus conventional autopsy in fetuses and children: a prospective validation study. Lancet 2013;382 (9888):223-233

20 Arthurs OJ, Thayyil S, Pauliah SS, et al; Magnetic Resonance Imaging Autopsy Study (MaRIAS) Collaborative Group. Diagnostic accuracy and limitations of post-mortem MRI for neurological abnormalities in fetuses and children. Clin Radiol 2015;70(08):872-880

21 Cohen MC, Paley MN, Griffiths PD, Whitby EH. Less invasive autopsy: benefits and limitations of the use of magnetic resonance imaging in the perinatal postmortem. Pediatr Dev Pathol 2008;11(01):1-9

22 Griffiths PD, Variend D, Evans M, et al. Postmortem MR imaging of the fetal and stillborn central nervous system. AJNR Am J Neuroradiol 2003;24(01):22-27

23 Cannie M, Votino C, Moerman P, et al. Acceptance, reliability and confidence of diagnosis of fetal and neonatal virtuopsy compared with conventional autopsy: a prospective study. Ultrasound Obstet Gynecol 2012;39(06):659-665

24 Boecking CA, Drey EA, Kerns JL, Finkbeiner WE. Correlation of prenatal diagnosis and pathology findings following dilation and evacuation for fetal anomalies. Arch Pathol Lab Med 2017;141 (02):267-273 